
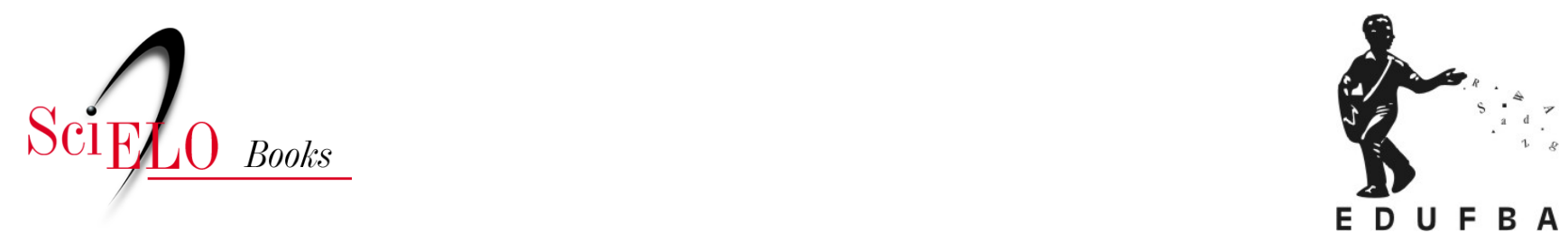

\title{
Características do trabalho e condições de saúde dos delegados de polícia civil
}

\author{
Gerfson Moreira Oliveira \\ Tânia Maria de Araújo \\ Fernando Martins Carvalho
}

\section{SciELO Books / SciELO Livros / SciELO Libros}

OLIVEIRA, G.M., ARAÚJO, T.M., and CARVALHO, F.M. Características do trabalho e condições de saúde dos delegados de polícia civil. In: FERNANDES, R.C.P., LIMA, M.A.G., and ARAÚJO, T.M., comps. Tópicos em saúde, ambiente e trabalho: um olhar ampliado [online]. Salvador: EDUFBA, 2014, pp. 53-75. ISBN: 978-65-5630-012-2. https://doi.org/10.7476/9786556300122.0005. \section{International license.}

All the contents of this work, except where otherwise noted, is licensed under a Creative Commons Attribution 4.0

Todo o conteúdo deste trabalho, exceto quando houver ressalva, é publicado sob a licença Creative Commons Atribição 4.0. 


\section{Características do trabalho e condições de saúde dos delegados de polícia civil}

Gerfson Moreira Oliveira

Tânia Maria de Araújo

Fernando Martins Carvalho

\section{Introdução}

No Brasil, produções científicas recentes sobre profissionais da segurança pública contribuem para aprofundar a compreensão de seu contexto profissional, suas condições de saúde/doença, relação com os determinantes sociais e seu impacto na saúde pública. (MINAYO; SOUZA, 2003; MINAYO; SOUZA; CONSTANTINO, 2008)

A organização do trabalho da polícia civil repercute na saúde destes trabalhadores que apresentam alta prevalência de doenças físicas e mentais. O trabalho da polícia civil baseia-se em prescrições burocráticas e disciplinares bastante restritivas, o que diminui a possibilidade de intervenções do indivíduo sobre o próprio trabalho. Além disso, existe a precarização do trabalho, falta de recursos materiais, humanos e políticas de segurança públicas ineficientes. (MINAYO; SOUZA, 2003)

Sinais de adoecimento físico, níveis elevados de estresse e sintomas psicológicos são frequentemente encontrados em policiais. Estes profissionais apresentam maior risco de desenvolver estresse pós-traumático (resultante da frequente exposição a traumas), síndrome de burnout (resultante da forma como está organizado o trabalho), problemas psicossociais (como representações conflitivas da profissão e baixa autoestima) e suicídio. (KELLEY, 2005; STURAR, 2008; ANDRADE; SOUZA; MINAYO, 2009)

Os estudos sobre trabalho policial e saúde abordam, em sua maioria, os agentes de polícia civil e militar e, menos frequentemente, os 
delegados de polícia. Os delegados têm atribuições específicas no setor de segurança pública e vivenciam dificuldades no ambiente de trabalho que afetam a saúde, a qualidade de vida e provocam adoecimento.

Delegados de polícia civil constituem um grupo ocupacional de grande vulnerabilidade entre as carreiras jurídicas brasileiras. Vários fatores se articulam para produzir este quadro como as características profissionais, psicossociais, políticas e institucionais do trabalho desenvolvido. (BONELLI, 2003)

Em um amplo estudo sobre o perfil dos delegados de polícia civil no Brasil, foram selecionadas amostras em nove estados brasileiros, entre eles, a Bahia. A pesquisa destacou importantes elementos sobre as características do trabalho destes profissionais, como dificuldades na gestão da instituição, baixo empenho dos governantes na implantação de políticas de segurança pública efetivas, falta de recursos para subsidiar o funcionamento da polícia civil, além de marginalização da instituição, com impactos na saúde e qualidade de vida dos delegados e no desenvolvimento das suas atividades. (SADEK; ARANTES, 2003)

Conhecer as características do trabalho e as condições de saúde/ doença deste grupo ocupacional poderá ser útil para fundamentar medidas de proteção à saúde desses profissionais e de reordenamento do trabalho, visando melhorar a qualidade da atenção prestada à população.

O objetivo deste estudo foi descrever as características do trabalho e as condições de saúde dos delegados de polícia civil da cidade de Salvador, Bahia, Brasil.

\section{Método}

Foi realizado um estudo epidemiológico de corte transversal com delegados e delegadas da polícia civil, em efetivo exercício profissional nos diversos cargos dos setores técnico-administrativos, delegacias especializadas e circunscricionais, localizados na cidade de Salvador, Bahia.

O critério de inclusão dos sujeitos foi estar em pleno exercício profissional e concordar em participar da pesquisa. Dos 165 delegados da capital, passíveis de serem incluídos no estudo, 152 (92,2\%) participaram da entrevista e responderam ao questionário. Oito $(4,8 \%)$ delegados não aceitaram participar e cinco (3,0\%) não foram localiza- 
dos durante a coleta de dados. As entrevistas foram realizadas por três psicólogos treinados, entre os meses de maio e setembro de 2010.

A participação dos delegados de polícia foi voluntária e as informações foram coletadas por meio de entrevistas e aplicação de questionário no ambiente de trabalho, em local reservado.

O questionário padronizado contemplou cinco blocos de questões com informações sobre: a) características sociodemográficas e estilo de vida; b) informações gerais sobre a atividade profissional incluindo questões relacionadas aos aspectos psicossociais do trabalho (medidos pelo Job Content Questionnaire - JCQ); c) informações sobre a saúde geral (contendo questões sobre a percepção do estado de saúde, uso de medicações, diagnóstico médico prévio, queixas de saúde e utilização do serviço médico da instituição); d) informações sobre a saúde mental, utilizando-se o Self-Reporting Questionnaire - SRQ-20; e) segurança laboral com questões sobre segurança pessoal no trabalho e violência. (KARASEK, 1993; ARAÚJO; KARASEK, 2008; MARI; WILLIAMS, 1986) Para detectar uso abusivo de álcool, o questionário C.A.G.E. foi incluído no bloco sobre estilo de vida. Para alcançar maior especificidade (menor número de falsos positivos) foi adotado o ponto de corte de duas ou mais respostas positivas, conforme critérios adotados em outras pesquisas com trabalhadores que identificaram sensibilidade de 88\% e especificidade de 83\%. (MANSUR; MONTEIRO, 1983; AMARAL; MALBERGIER, 2004)

O JCQ traduzido como Questionário sobre o Conteúdo do Trabalho, utilizado para avaliar aspectos psicossociais do trabalho, direciona-se especificamente à estrutura social e psicológica de atividades profissionais diversas, sendo também utilizado para relacionar situações de trabalho a doenças ocupacionais. (ARAÚJO; GRAÇA; ARAÚJO, 2003)

O JCQ fundamenta-se teoricamente no Modelo Demanda-Controle (MDC), que postula uma relação entre nível de controle do trabalhador sobre o processo de trabalho e as exigências psíquicas relativas à execução das tarefas. A combinação desses dois fatores estabelece quatro situações distintas no trabalho: alta exigência (alta demanda psicológica e baixo controle); trabalho ativo (alta demanda e alto controle); trabalho passivo (baixa demanda e baixo controle) e baixa exigência (baixa demanda e alto controle). Cada uma destas situações resultaria em implicações 
diferenciadas no desempenho das tarefas e na saúde dos trabalhadores, sendo as situações de trabalho ativo e baixa exigência condições mais favoráveis e as situações de alta exigência e de trabalho passivo as que oferecem maior risco à saúde física e mental e ao comprometimento no desenvolvimento profissional. (ARAÚJO et al., 2006) Nesta pesquisa, foi utilizada versão validada para trabalhadores no Brasil. (ARAÚJO; KARASEK, 2008)

Para obtenção dos indicadores psicossociais do trabalho propostos neste modelo, as escalas foram construídas conforme orientação do manual do JCQ. (KARASEK, 1993) Para composição dos grupos do modelo demanda-controle, as escalas foram dicotomizadas adotando-se a mediana como ponto de corte. Os resultados encontrados serviram de referência para classificação dos sujeitos nos quadrantes do modelo: baixa exigência, trabalho ativo, trabalho passivo e alta exigência. (ARAÚJO; GRAÇA; ARAÚJO, 2003)

O instrumento utilizado para avaliar a saúde mental foi o SRQ-20. O SRQ-20 é indicado para estudos populacionais; é um instrumento de triagem de transtornos mentais comuns (TMC). TMC é uma expressão criada por Goldberg e Huxley (1992) para designar sintomas não psicóticos como diminuição de energia, irritabilidade, dificuldade de concentração, humor deprimido/ansioso, sintomas somáticos e pensamentos depressivos, que evidenciam vulnerabilidade das condições de saúde mental do indivíduo, mas não se configuram, necessariamente, como um diagnóstico clínico. Os TMC são considerados como problema de saúde pública devido ao impacto na qualidade de vida e no trabalho das pessoas, além das demandas geradas nos serviços de saúde. (GOLEDBERG; HUXLEY, 1993; COUTINHO; ALMEIDA FILHO; MARI, 1999) Na população brasileira, o SRQ-20 foi utilizado para avaliar TMC em diferentes ocupações como gestores professores e policiais civis. (BRANT; DIAS, 2004; REIS et al., 2008; SOUZA et al., 2007)

Diferentes pontos de corte têm sido adotados em pesquisas com o SRQ-20 com valores que variam de 5 a 8 pontos para suspeição de TMC conforme o sexo, com pontos de corte menores na população masculina $(5 / 6)$ e maiores na população feminina (7/8). (FERNANDES et al., 2002) Conforme outras pesquisas, neste estudo foram adotados pontos de corte diferenciados para homens e mulheres: para os delegados adotou-se ponto de cinco ou mais questões positivas; para as delega- 
das adotou-se ponto de sete ou mais questões positivas. (FERNANDES et al., 2002; PALMA et al., 2009)

A análise dos dados incluiu informações sociodemográficos (idade, sexo, nível de instrução, renda), estilo de vida (uso de cigarro, prática de esporte e atividades regulares de lazer), condições de saúde geral, características profissionais e segurança no trabalho, assim como aspectos psicossociais do trabalho. A prevalência de transtornos mentais comuns e a de uso abusivo de álcool foram estimadas. Os questionários foram numerados e tabulados utilizando-se o programa Statistical Package for the Social Sciences (SPSS), versão 9.0 para Windows. Após digitação, cada formulário passou por dupla revisão.

Com o objetivo de preservar a identidade dos sujeitos da pesquisa, manteve-se o anonimato do(a) delegado(a) no preenchimento do questionário. O estudo foi aprovado pelo Comitê de Ética do Hospital São Rafael (processo no CE CEP/HSR 41/09) em 07/12/2009.

\section{Resultados}

Os delegados de polícia civil de Salvador, Bahia tinham média de idade de 45,7 anos ( $D P=9$ ), estando $59,8 \%$ na faixa etária entre 40 e 59 anos. Nesta população, mais da metade $(59,9 \%)$ era do sexo feminino; $62,5 \%$ declararam ser casado ou ter união estável e 75,6\% tinham filhos. Quanto à formação profissional, $75 \%$ possuíam algum tipo de pós-graduação (especialização: 67,8\% e mestrado/doutorado: 7,2\%). A renda média variou de $\mathrm{R} \$ 5.000,00$ a $\mathrm{R} \$ 8.000,00$ para $59,8 \%$ do grupo. A prática de atividade física regular (igual ou superior a três vezes na semana) foi referida por $42,1 \%$ dos respondentes; $75,5 \%$ mantinham algum tipo de atividade de lazer semanalmente. O hábito de fumar foi referido por $11,8 \%$ dos delegados; $48,6 \%$ relataram consumo de bebida alcoólica (eventual ou regular) e 7,2\% do total de delegados foram classificados pelo CAGE como suspeitos de uso abusivo do álcool. A utilização de drogas ilícitas nos últimos 10 anos foi referida por $3,3 \%$ dos entrevistados.

Dos 152 delegados de polícia civil, a média de tempo de trabalho na carreira foi de 17,35 anos ( $\mathrm{DP}=9,04$ anos) e a carga horária total de trabalho foi de 42,5 horas semanais ( $\mathrm{DP}=6,8$ horas); $12 \%$ dos entrevistados exerciam atividades remuneradas fora da polícia. A maioria dos 
delegados tinha como atividade principal a execução de tarefas administrativas $(63,2 \%)$ e a jornada de trabalho predominante no grupo era de oito horas por dia $(65,1 \%)$.

Tabela 1 - Características do trabalho de 152 delegados de polícia civil de Salvador, Bahia, 2010.

\begin{tabular}{l|c|c}
\multicolumn{1}{c|}{ Características do Trabalho } & $\mathbf{n}$ & $\%$ \\
\hline Tipo de função & & \\
\hline Funções técnicas de caráter administrativo & 96 & 63,2 \\
\hline Funções técnicas com ênfase operacional & 56 & 36,8 \\
\hline Carga horária de trabalho & & \\
\hline Somente horário administrativo - 8horas por dia & 99 & 65,1 \\
\hline Somente regime de plantão de 12 e/ou 24 horas de trabalho & 32 & 21,0 \\
\hline Horário administrativo e plantão & 21 & 13,8 \\
\hline Jornada de trabalho & & \\
\hline Ser requerido a fazer horas extras com frequência & 42 & 27,6 \\
\hline Regime de sobre aviso & 39 & 25,7 \\
\hline
\end{tabular}

Fonte: (OLIVEIRA; ARAÚJO; CARVALHO, 2010).

Sobre as condições de trabalho, 52,6\% dos delegados afirmaram não dispor, ou dispor com pouca frequência, de equipamentos suficientes e adequados para realização das atividades. Em relação ao reconhecimento e satisfação no trabalho, $52,0 \%$ não se sentiam reconhecidos e $35,5 \%$ não estavam satisfeitos com o trabalho realizado, sendo que $21,1 \%$ dos delegados não se candidatariam ao seu emprego novamente.

Quanto aos aspectos psicossociais do trabalho, 55,3\% dos delegados tinham baixo controle sobre o trabalho; alta demanda psicológica foi relatada por $50,0 \%$ dos profissionais e $46,0 \%$ referiram baixo suporte social. Referindo-se ao controle sobre o seu trabalho, $61,2 \%$ dos delegados consideraram a sua atividade repetitiva; a impossibilidade de tomar suas próprias decisões foi o item mais referido na dimensão de controle relativo à autoridade decisória $(41,5 \%)$. O trabalho excessivo e a exigência de rapidez perceptiva foram os itens de demanda psicológica mais citados pelos delegados $(75,6 \%$ e $69,1 \%$, respectivamente). 
Dentre os fatores que compõem o suporte social, destacou-se a falta de auxílio do superior na realização das tarefas $(47,4 \%)$ e a falta de preocupação do superior com o bem estar da equipe $(36,2 \%)$.

Considerando os quadrantes do Modelo Demanda Controle, observou-se maior frequência da dimensão "trabalho passivo" (29,6\%), seguida de "trabalho de alta exigência" (25,7\%). As frequências correspondentes aos aspectos psicossociais do trabalho são apresentadas na Tabela 2.

Tabela 2 - Frequência de respostas afirmativas sobre aspectos psicossociais do trabalho, segundo dimensões do Modelo Demanda-Controle, por 152 delegados de polícia civil de Salvador, Bahia, 2010.

\begin{tabular}{|c|c|c|}
\hline Questões do JCQ (referência) & $\mathbf{n}$ & $\%$ \\
\hline \multicolumn{3}{|l|}{ CONTROLE SOBRE O TRABALHO } \\
\hline Baixo controle & 84 & 55,3 \\
\hline Alto controle & 68 & 44,7 \\
\hline \multicolumn{3}{|l|}{ Uso de habilidades } \\
\hline Trabalho repetitivo & 93 & 61,2 \\
\hline Impossibilidade de fazer diferentes tarefas & 59 & 38,8 \\
\hline Não desenvolve habilidades próprias & 55 & 36,2 \\
\hline Trabalho não requer que aprenda coisas novas & 13 & 8,6 \\
\hline Trabalho não requer alto nível de habilidade & 10 & 6,6 \\
\hline \multicolumn{3}{|l|}{ Autoridade Decisória } \\
\hline Não permite tomar as próprias decisões & 63 & 41,5 \\
\hline O que diz sobre o trabalho não é considerado & 40 & 26,3 \\
\hline Pouca liberdade de decisão sobre o próprio trabalho & 31 & 20,4 \\
\hline Não ser criativo no trabalho & 17 & 11,2 \\
\hline \multicolumn{3}{|l|}{ DEMANDA PSICOLÓGICA NO TRABALHO } \\
\hline Alta demanda & 76 & 50,0 \\
\hline Baixa demanda & 76 & 50,0 \\
\hline Demandas psicológicas & & \\
\hline
\end{tabular}




\begin{tabular}{|c|c|c|}
\hline Trabalho excessivo & 115 & 75,6 \\
\hline Trabalho requer muita rapidez & 105 & 69,1 \\
\hline Tempo insuficiente para executar as tarefas & 99 & 65,1 \\
\hline Demandas conflitantes no trabalho & 89 & 58,5 \\
\hline \multicolumn{3}{|l|}{ SUPORTE SOCIAL NO TRABALHO } \\
\hline Alto suporte & 82 & 54,0 \\
\hline Baixo suporte & 70 & 46,0 \\
\hline \multicolumn{3}{|l|}{ Suporte da chefia } \\
\hline Superior imediato não auxilia na realização de tarefas & 72 & 47,4 \\
\hline Superior imediato não se preocupa com o bem estar da equipe & 55 & 36,2 \\
\hline Tratamento com falta de respeito do superior imediato & 12 & 7,9 \\
\hline \multicolumn{3}{|l|}{ Suporte de colegas } \\
\hline Não recebe ajuda de colegas de trabalho & 25 & 16,4 \\
\hline Colegas de trabalho não são amigáveis & 14 & 9,2 \\
\hline Falta de respeito dos colegas de trabalho & 5 & 3,3 \\
\hline \multicolumn{3}{|l|}{ QUADRANTES DO MODELO DEMANDA-CONTROLE } \\
\hline Trabalho de baixa exigência (baixa demanda + alto controle) & 31 & 20,4 \\
\hline Trabalho passivo (baixa demanda + baixo controle) & 45 & 29,6 \\
\hline Trabalho ativo (alta demanda + alto controle) & 37 & 24,3 \\
\hline Trabalho com alta exigência (alta demanda + baixo controle) & 39 & 25,7 \\
\hline
\end{tabular}

Fonte: (OLIVEIRA; ARAÚJO; CARVALHO, 2010).

Quando questionados em relação ao estado de saúde, 95,4\% consideravam que a sua saúde era boa e 4,6\% referiram ter saúde ruim. O uso atual de medicação ansiolítica foi referido por 10,5\% dos participantes, sendo que $27,7 \%$ afirmaram já ter feito uso de medicação no passado. Dos 152 delegados, $86,2 \%$ registraram diagnóstico médico de uma ou mais doenças nos últimos 30 dias. As principais doenças diagnosticadas foram: gastrite $(34,9 \%)$, varizes $(27,7 \%)$, hipertensão arterial sistêmica 
$(25,7 \%)$, depressão $(21,1 \%)$ e artrite $(20,3 \%)$, conforme apresentado na Tabela 3.

Tabela 3 - Frequência de diagnósticos médicos referidos por 152 delegados de polícia civil de Salvador, Bahia, Brasil, 2010.

\begin{tabular}{l|l|l}
\hline \multicolumn{1}{c|}{ Diagnósticos médicos } & n & \multicolumn{1}{c}{$\%$} \\
\hline Gastrite & 53 & 34,9 \\
\hline Varizes & 41 & 27,7 \\
\hline Hipertensão Arterial Sistêmica & 39 & 25,7 \\
\hline Depressão & 32 & 21,1 \\
\hline Artrite & 31 & 20,3 \\
\hline Hérnia de Disco & 26 & 17,1 \\
\hline LER-DORT & 15 & 9,9 \\
\hline Doença dos rins & 14 & 9,2 \\
\hline Hipotireoidismo & 12 & 7,9 \\
\hline Outros & 55 & 36,2 \\
\hline Não tem diagnóstico médico de doença & 21 & 13,8 \\
\hline
\end{tabular}

Fonte: (OLIVEIRA; ARAÚJO; CARVALHO, 2010).

A prevalência global de TMC foi de $37,5 \%$, variando segundo o sexo: $41 \%$ entre os delegados e $35 \%$ entre as delegadas. As questões do SRQ-20 com maiores proporções de respostas positivas estavam no grupo referente a "humor deprimido/ansioso" e "sintomas somáticos".

Tabela 4 - Frequência de respostas afirmativas às perguntas do Self-Reporting Questionnaire-20

(SRQ-20), por 152 delegados de polícia civil de Salvador, Bahia, Brasil, 2010.

\begin{tabular}{l|c|c}
\multicolumn{1}{c|}{ Informações do SRQ-20 } & $\mathbf{n}$ & $\%$ \\
\hline Sintomas somáticos & & \\
\hline Dormir mal & 72 & 47,4 \\
\hline Ter sensações desagradáveis no estômago & 57 & 37,5 \\
\hline Ter dores de cabeça freqüentes & 53 & 34,9 \\
\hline
\end{tabular}




\begin{tabular}{|c|c|c|}
\hline Ter má digestão & 49 & 32,2 \\
\hline Ter falta de apetite 2 & 24 & 15,8 \\
\hline Ter tremores nas mãos & 11 & 7,2 \\
\hline \multicolumn{3}{|l|}{ Diminuição da energia } \\
\hline Sente-se cansado o tempo todo & 54 & 35,5 \\
\hline Dificuldade para realizar, com satisfação, as tarefas diárias & 49 & 32,2 \\
\hline Se cansar com facilidade & 46 & 30,3 \\
\hline Trabalho diário causa sofrimento & 31 & 20,4 \\
\hline Ter dificuldade para tomar decisões & 22 & 14,5 \\
\hline Ter dificuldade para pensar com clareza & 22 & 14,5 \\
\hline \multicolumn{3}{|l|}{ Humor deprimindo/ansioso } \\
\hline Sente-se nervoso, tenso ou preocupado & 88 & 57,9 \\
\hline Ter se sentido triste ultimamente & 57 & 37,5 \\
\hline Assusta-se com facilidade & 38 & 25,0 \\
\hline Ter chorado mais do que de costume & 16 & 10,5 \\
\hline \multicolumn{3}{|l|}{ Pensamentos depressivos } \\
\hline Ter perdido o interesse pelas coisas & 26 & 17,1 \\
\hline Ser incapaz de desempenhar um papel útil na vida & 6 & 3,9 \\
\hline Sente-se uma pessoa inútil na vida & 6 & 3,9 \\
\hline Ter idéia de acabar com a própria vida & 3 & 2,0 \\
\hline
\end{tabular}

Fonte: (OLIVEIRA; ARAÚJO; CARVALHO, 2010).

No momento da realização do estudo, $39,5 \%$ dos delegados estavam em tratamento médico por algum motivo e $7,2 \%$ referiram acompanhamento psicológico. A não utilização do serviço de saúde ocupacional da polícia civil foi referida por $84,9 \%$ dos delegados; $98,7 \%$ referiram não utilizar o serviço de psicologia da polícia. 


\section{Discussão}

Os delegados de polícia civil de Salvador compõem uma população de meia-idade com predomínio do sexo feminino, com união estável, filhos e formação profissional com nível de especialização. Esses dados de faixa etária, situação conjugal e número de filhos convergem com o perfil dos delegados de polícia do Brasil. Entretanto, delegados de Salvador apresentaram maior nível de escolaridade e mais mulheres na profissão, em relação ao estudo nacional, que identificou titulação máxima de graduação e apenas $17,1 \%$ de mulheres. (SADEK; ARANTES, 2003)

A inserção de mulheres na área de segurança pública teve início a partir do século XX e seu aumento tem sido justificado pela maior participação feminina no mercado de trabalho, pelas políticas de ações afirmativas e leis antidiscriminatórias e de proteção às mulheres. (SILVEIRA, 2009; ROSA; BRITO; OLIVEIRA, 2007) No Brasil, algumas pesquisas ressaltam que as "habilidades femininas" de comunicação, adaptação e flexibilidade também foram responsáveis pela maior abertura das instituições policiais às mulheres, uma vez que elas poderiam contribuir para a melhoria da imagem da polícia na sociedade, tradicionalmente percebida como: machista, violenta e totalitária. (HAGEN, 2005; SILVEIRA, 2009)

Esta inserção, entretanto, não se deu de forma tranquila, uma vez que as mulheres tiveram que alinhar os seus comportamentos a uma cultura organizacional fortemente marcada por valores masculinos e mecanismos rígidos de mediação das relações de trabalho. (ROSA; BRITO; OLIVEIRA, 2007) Estudo realizado com policiais do Rio Grande do Sul relatou que a participação feminina na polícia civil ocasionou uma divisão sexual do trabalho, onde as mulheres tenderiam a ser afastadas de atividades de enfrentamento (ênfase operacional) e destinadas a funções de caráter mais burocrático (ênfase administrativa), desenvolvidas no âmbito das delegacias e não em atividades de rua. (HAGEN, 2005) Embora o perfil dos delegados pesquisados em Salvador apresente maior número de profissionais exercendo atividades administrativas, quando se observa os dados por grupo de gênero, $41 \%$ dos delegados entrevistados estavam exercendo atividades mais operacionais, sendo que esta proporção entre as delegadas da pesquisa foi de $34 \%$. Contudo, o fato 
de terem sido selecionadas apenas unidades lotadas na capital pode ter influenciado nestes resultados.

Quanto às delegadas da cidade de Salvador e São Paulo, pesquisas realizadas nestas capitais, ressaltaram desequilíbrio proporcional entre homens e mulheres na profissão no que se refere à ocupação de postos mais elevados na hierarquia profissional. Apesar de ter havido aumento expressivo de delegadas, existe maior numero de delegados no topo da categorial profissional. (BAHIA, 2002; SILVEIRA, 2009)

Para o exercício do cargo de delegado de polícia civil é necessária graduação em Direito. O elevado nível de escolaridade entre os delegados indica busca de qualificação e aprimoramento, já que a maioria relatou ter curso de pós-graduação. Dentre outros fatores de motivações pessoais para busca do conhecimento, o auxílio em gratificações de até $20 \%$ sobre o salário pode ser um importante incentivo para este nível elevado na qualificação dos delegados.

A renda referida por estes profissionais foi heterogênea. Disparidades de remuneração entre delegados nos diversos estados brasileiros, além de defasagem em relação às demais carreiras jurídicas, foram apontadas em outros estudos, como motivo de insatisfação e justificativa para o exercício de outras atividades profissionais remuneradas, em paralelo, além da polícia. (SADECK; ARANTES, 2003) Atividades remuneradas fora da polícia civil também foram referidas pelos delegados entrevistados, sendo a docência a ocupação mais exercida.

De modo geral, mais da metade dos delegados praticava atividade física com regularidade, mantinha atividades de lazer semanalmente e referiu não ter o hábito de fumar. A prática de atividade física regular foi superior aos dados encontrados em pesquisas com policiais civis e militares do Rio de Janeiro $(13,1 \%)$ e para a população de Salvador (13,8\%). (MINAYO; SOUZA; CONSTANTINO, 2008; BRASIL, 2009) A frequência de tabagismo entre os delegados foi similar à população soteropolitana $(11,3 \%)$ e menor que a da população brasileira $(15,5 \%)$. (BRASIL, 2009) A frequência do consumo de álcool e a suspeição de alcoolismo entre os delegados foram inferiores ao resultado encontrado em agentes penitenciários $(68,5 \%)$, porém, superior ao observado para a população soteropolitana (5,6\%). (SILVA; VIEIRA, 2008; FERNANDES, et al., 2002; BRASIL, 2009) 
A utilização de drogas ilícitas por delegados de Salvador foi menos frequente do que por policiais que atuavam em unidades penitenciárias no Canadá (14,7\%). (LAVIGNE; BOURBONNAIS, 2010) O relato de consumo de substâncias psicotrópicas em pesquisas com profissionais da segurança pública, entretanto, deve ser avaliado com cuidado já que, apesar da garantia de anonimato, os dados podem estar subestimados. O frequente contato de profissionais da segurança pública com traficantes e usuários de drogas, e a sua potencial vulnerabilidade nas estruturas informais de poder poderiam influenciar no uso de drogas. (FERNANDES et al., 2002) As condições de vulnerabilidade no trabalho, como baixo suporte de colegas e supervisores e relações de desequilíbrio entre esforço e recompensa, associam-se ao uso de drogas entre policiais. (LAVIGNE; BOURBONNAIS, 2010)

O tempo de trabalho como delegado de polícia foi longo, representando a situação de estabilidade como servidores públicos. No entanto, é importante ressaltar que o fato de possuírem estabilidade na instituição não garante a estabilidade na função. Os delegados podem ser transferidos ou remanejados para os mais diversos setores e localidades na corporação de acordo com os interesses da administração pública, que por sua vez, estão vinculadas às estratégias políticas do governo vigente. A interferência política partidária na cúpula da polícia civil tem sido considerada como obstáculo ao bom funcionamento da instituição, assim como na eficácia da segurança pública no país. (SADEK; ARANTES, 2003; HAGEN, 2005) A lei orgânica da polícia civil (BAHIA, 2009) prevê mecanismos para promoção e desenvolvimento profissional, minimizando a influência de interesses políticos na carreira do delegado; entretanto, na Bahia, a lei foi aprovada em fevereiro de 2009 e ainda não foi plenamente efetivada.

A carga horária semanal de trabalho referida foi compatível com o estabelecido em outras profissões. Entretanto, a maioria dos delegados sente fadigada ao fim de uma jornada de trabalho, o que sugere uma atividade profissional de elevada exigência. Três situações importantes podem estar relacionadas a esta queixa: a) o regime de plantão de até 24 horas ininterruptas praticadas por $35 \%$ dos delegados. Isto requer prontidão perceptiva e disposição para vivenciar longa jornada de trabalho, uma vez que precisam estar em alerta para responder, prontamente, aos mais diversos tipos de ocorrências; b) a prática de outras 
atividades remuneradas exercidas em horários de folga dos delegados, que pode comprometer o descanso efetivo dos profissionais; c) a prática frequente de horas extras, que revela limitação no efetivo do número de delegados na capital, sobrecarga de trabalho, acúmulo de funções e potencialização dos riscos aos quais estão submetidos. Escalas de plantão de 24 horas foram consideradas pelos policiais civis e militares, do Rio de Janeiro, como principal causa de cansaço, irritabilidade, insônia e desgaste mental. (MINAYO; SOUZA; CONSTANTINO, 2008)

Elevada proporção dos delegados afirmou não dispor de equipamentos suficientes e adequados para realização de suas atividades. A falta de equipamentos e recursos (materiais, financeiros e humanos) para desenvolver as atividades profissionais tem sido um dos principais problemas enfrentados pelos profissionais da segurança pública no Brasil. (MIANAYO; SOUZA; CONSTANTINO, 2008) Equipamentos danificados, viaturas sem manutenção adequada, rádios quebrados, ausência de salas de repouso, falta de treinamentos e de pessoal qualificado são algumas das dificuldades apontadas nas pesquisas realizadas no setor. (MINAYO; SOUZA, 2003; SADEK; ARANTES, 2003) Estas condições podem explicar porque elevada proporção dos delegados não se sentiam reconhecidos no trabalho e não estavam satisfeitos com as atividades profissionais.

O baixo controle sobre o próprio trabalho, referido por percentual elevado de delegados, revelou características de um trabalho repetitivo e de pouca autonomia profissional. De modo geral, quando as atividades são desenvolvidas em delegacias, o delegado tem função de chefia, de gestão, o que implicaria em maior autonomia no trabalho. Porém, nesta pesquisa, mais de $60 \%$ dos delegados entrevistados atuavam em unidades técnicas administrativas realizando tarefas mais burocráticas e rotineiras, comandados e supervisionados, o que explicaria, em parte, os resultados apresentados. A estrutura organizacional das polícias civil e militar ainda é tradicional, com forte referência da administração pública burocrática, pautada na hierarquia e na disciplina. A organização do trabalho da polícia, baseada neste modelo de gestão, dá maior importância aos aspectos formais da instituição, gerando uma visão fragmentada do trabalho, com pouco destaque para os trabalhadores. Somado a estas questões, existe o componente de precarização do trabalho que coloca o policial no centro de forças conflitivas constantes, 
o que desencadeia consequências danosas para a sua saúde física e mental. (SILVA; VIEIRA, 2008)

Os dados sobre suporte social caracterizaram uma população que recebe apoio dos colegas de trabalho indicando um clima colaborativo estabelecido entre os delegados e a sua equipe de trabalho. Para alguns estudiosos da atividade policial, o perigo da profissão torna o policial isolado socialmente devido à sua desconfiança em relação às pessoas, o que favoreceria uma maior solidariedade com os colegas de trabalho. (REINER, 2000; MINAYO; SOUZA, 2003) Porém, cabe destacar que um percentual significativo dos entrevistados referiu não receber apoio do superior imediato na realização das tarefas, nem perceberam preocupação dos chefes com o bem estar da equipe. Estes resultados convergem com os resultados obtidos em estudo realizado com policiais do Recife que identificaram falta de apoio dos superiores no contexto de trabalho. (FERREIRA; AUGUSTO; SILVA, 2008) A falta de apoio da chefia e o precário empenho governamental no fortalecimento das instituições policiais (civil e militar) têm sido evidenciados por diversas pesquisas com estes profissionais no Brasil, sendo considerado como um dos principais obstáculos ao bom funcionamento da segurança pública no país. (SADEK; ARANTES, 2003; MINAYO; SOUZA; CONSTANTINO, 2008)

Alta demanda psicológica foi identificada no grupo estudado. Apesar de nem todas as tarefas envolverem perigo, muitos delegados percebiam o trabalho como de elevada exigência psicológica por terem que trabalhar com demandas conflitantes, de forma excessiva e com ritmo acelerado. Exigências psicológicas excessivas desencadeiam doenças físicas e psíquicas que comprometem a saúde e a qualidade de vida dos trabalhadores. Neste contexto, as corporações policiais se destacam da população em geral e de outras categorias profissionais pela pesada carga de trabalho e sofrimento, justificando, portanto, um maior desgaste físico e mental. (MINAYO; SOUZA; CONSTANTINI, 2008)

A dimensão do modelo demanda/controle mostrou maior frequência de delegados em situações de trabalho passivo (baixo controle e baixa demanda), seguidos de trabalho de alta exigência (baixo controle e alta demanda). Estes dados encontrados sugerem que a maioria dos delegados do estudo, vivencia experiências de trabalho consideradas desfavoráveis ao desempenho ocupacional saudável e à satisfação 
profissional. De acordo com as referências (MDC), a experiência profissional na condição de trabalho passivo pode conduzir ao declínio na atividade global do indivíduo e à redução da capacidade de produzir soluções para as atividades e problemas enfrentados. Já a condição do trabalho de alta exigência apresenta maior risco para o aparecimento de problemas de ordem psicológica e doenças como fadiga, ansiedade, depressão e doenças físicas. (ARAÚJO; GRAÇA; ARAUJO, 2003).

Os principais diagnósticos de saúde referidos estavam relacionados com aspectos psicossomáticos e de saúde mental, disfunções do aparelho circulatório e vascular e doenças do sistema osteoarticular. Queixas relacionadas à saúde mental, disfunções do aparelho circulatório e do sistema osteoarticular, são convergentes com outras pesquisas com policiais. (MINAYO; SOUZA; CONSTANTINO, 2008)

A prevalência de TMC foi elevada quando comparada a estudos com policiais civis $(20,2 \%)$ e agentes penitenciários de Salvador (30,7\%). (MINAYO; SOUZA, 2003; FERNANDES et al., 2002) Dentre os sintomas mais referidos, destacaram-se os relacionados ao humor deprimido/ansioso, questões psicossomáticas e diminuição de energia. Problemas psicossomáticos e de saúde mental são, frequentemente, encontrados em policiais, sendo os sintomas psicológicos apontados como os de maior prevalência. (STURAR, 2008)

Estudos realizados com policiais militares e agentes penitenciários identificaram maior propensão ao sofrimento psíquico entre as mulheres policiais. (MORAES et al., 2001; SANTOS et al., 2010) Neste estudo, no entanto, destacou-se prevalência de TMC um pouco mais elevada em delegados quando comparados às delegadas. Souza e colaboradores (2007) não identificaram diferenças significativas na prevalência de TMC em policiais civis conforme o gênero, porém, ressaltaram que o sofrimento psíquico é maior entre aqueles que exerciam atividades operacionais e que os homens policiais percebiam mais situações de risco no trabalho do que as colegas de profissão. Em nossos achados, a proporção de delegados exercendo atividades operacionais (de maior exposição à criminalidade) foi maior do que a de delegadas. Este fato pode justificar, em parte, os resultados encontrados. No entanto, ressaltamos que diferentes características e contextos do trabalho destas profissionais podem interferir na comparação entre os estudos. Destaca-se, ainda, que o aprofundamento acerca dos aspectos relacionados 
ao gênero e repercussões na saúde mental constitui foco relevante para estudos futuros.

Apesar do perfil de saúde apresentado, com expressiva proporção de indivíduos com TMC e diagnóstico médico referido de doenças, quando perguntados sobre a percepção das condições de saúde, quase a totalidade se considerava em bom estado de saúde. Observou-se, entretanto, que a vulnerabilidade das condições de saúde é frequente na rotina de trabalho desses profissionais e o reconhecimento de situações de tensão e fragilidade é ofuscado pela pressão de muitos delegados em sustentar uma imagem de "fortaleza" que não sucumbe frente às dificuldades. Para Dejours (1992), os trabalhadores tendem a controlar a doença diante de atividades profissionais adversas, desenvolvendo, coletivamente, mecanismos de defesas psicológicas que permitem que o trabalhador as domine, e em situações especificas, tenha menor consciência do seu adoecimento.

Quanto aos recursos e ações de saúde promovidas pela polícia civil a estes trabalhadores, percentual expressivo dos delegados não costumava utilizar o serviço médico ou de psicologia da polícia, tendo como principal justificativa o desconhecimento da existência dos mesmos. Estes dados sugerem que, dentre outros fatores, as ações de saúde ocupacional da polícia civil não são expressivas no grupo pesquisado, necessitando de maior investimento voltado à prevenção de agravos e promoção da saúde dos delegados.

De acordo com a Secretaria Nacional de Segurança Pública (SNSP), apesar da dedicação de alguns profissionais e a existência de programas pontuais de atenção à saúde do policial no Brasil, em quase todos os estados $(96,2 \%)$, a qualidade dos serviços de saúde ocupacional é precária, devido à carência de pessoal especializado, recursos materiais e falta de apoio superior. Os serviços de saúde avaliados oferecem maior atenção à saúde física, além das atividades não enfatizarem a prevenção de doenças e a promoção da saúde. (BRASIL, 2009)

O método de aplicação de questionário através da entrevista na realização desta pesquisa constituiu-se em uma oportunidade de escuta para estes trabalhadores. Observou-se, durante o trabalho de campo, a necessidade de expressão de queixas e conflitos relacionados tanto ao mundo do trabalho como à vida pessoal. O espaço de escuta como estratégia de fortalecimento emocional e suporte psicossocial, visando o 
manejo das situações de conflito e o aprimoramento da saúde dos profissionais da segurança pública, tem sido negligenciado pela maioria dos gestores da polícia, ao longo dos últimos anos no Brasil. (ANDRADE; SOUZA; MINAYO, 2009) Na Bahia, de acordo com a Academia de Polícia Civil (ACADEPOL), existem apenas três psicólogos para todo o efetivo de delegados de polícia, agentes de polícia e escrivães da polícia civil do estado.

Nossos achados devem ser considerados com cautela em função de possíveis vieses. Os estudos de corte transversal apresentam limitações, pois incluem apenas as pessoas que resistiram aos problemas de saúde apresentados e, por coletarem simultaneamente dados de exposição e de doença, não possibilitam apreensão de relação temporal entre ambas. Ainda existe a possibilidade de perdas de informações decorrentes de delegados que abandonaram a profissão por problemas de saúde relacionados ou não ao trabalho, e que, por alguma razão, estavam ausentes, afastados, ou tinham falecido no período de realização do estudo. Situações vivenciadas fora do contexto de trabalho também poderiam influenciar a saúde física e/ou mental dos indivíduos pesquisados.

Apesar do reduzido número de delegados participantes da pesquisa, obtivemos alta taxa de respostas. Para Minayo, Souza e Constantino (2008), limitações metodológicas são frequentes nas investigações realizadas com a polícia em todo o mundo, especialmente no Brasil, devido às restrições ao acesso de informações por parte das instituições e/ou pelo receio que os policiais têm de serem prejudicados quando informam sobre si próprios.

\section{Considerações finais}

Esta pesquisa revelou, dentre outros agravos, a magnitude dos problemas de saúde física e mental presentes no cotidiano dos profissionais estudados e as principais dificuldades enfrentadas no contexto de trabalho. Muitos destes problemas já foram ressaltados na literatura científica internacional e evidenciados nos estudos brasileiros com policiais civis. (MINAYO; SOUZA, 2003) Os resultados encontrados destacaram que, em sua maioria, os delegados de polícia civil pesquisados exerciam atividades administrativas, eram do gênero feminino e não se sentiam reconhecidos no trabalho. Com relação aos aspectos 
psicossociais do trabalho, observou-se predominância de situações envolvendo baixo controle sobre o próprio trabalho, maior demanda psicológica e baixo suporte social da chefia, configurando condições desfavoráveis na vivência profissional (trabalho passivo e trabalho de alta exigência). Verificou-se elevada ocorrência de problemas de saúde e alta prevalência de Transtornos Mentais Comuns (TMC) entre os delegados do estudo; registrou-se baixa utilização dos serviços de atenção integral à saúde disponibilizada pela instituição aos delegados de polícia, tanto em aspectos terapêuticos quanto em ações de prevenção de agravos e promoção da saúde; relataram, ainda, condições precárias de trabalho principalmente em relação aos equipamentos de segurança e proteção e apresentaram altas demandas físicas e emocionais na realização da atividade profissional.

O delegado de polícia civil exerce uma função de extrema importância no auxilio a justiça brasileira. Além das competências e habilidades investigativas, fundamentais na aplicação da justiça criminal e na repressão ao crime, este profissional lida com as mais diversas situações de conflitos e tensões tanto no seu contexto de trabalho como nas adversidades presentes nos centros urbanos do país. Daí a necessidade de cuidar dos aspectos institucionais que promovam o desenvolvimento de carreira e maior qualidade de vida no trabalho. Para Dejours (1992), quando a organização do trabalho não é opressora, estes sujeitos podem conjugar seus desejos e realizações pessoais e ou profissionais com as necessidades econômicas, com mais saúde e autonomia.

\section{Referências}

AMARAL, R.B.; MALBERGIER, A. Avaliação do C.A.G.E. Revista Brasileira de Psiquiatria, v. 26, n. 3, p. 156-163, 2004.

ANDRADE, E.R; SOUZA, E.R; MINAYO, M.C.S. Intervenção visando auto-estima e qualidade de vida dos policiais civis no Rio de Janeiro. Ciência e Saúde Coletiva, v. 14, n. 1, p. 275-285, 2009.

ARAÚJO, T.M; KARASEK, R. Validity and reliability of the job content questionnaire in formal and informal jobs in Brazil. Scandinavian

Journal of Work, Environment \& Health Suppl, n. 6, p. 52-59, 2008. 
ARAÚJO, T.M; GRAÇA, C.C; ARAÚJO, E. Estresse ocupacional e saúde: contribuições do modelo demanda-controle. Ciência

\& Saúde Coletiva, v. 8, n. 3, p. 285-297, 2003.

ARAÚJO, T.M. et al. Aspectos psicossociais do trabalho e distúrbios psíquicos entre trabalhadores de enfermagem.

Revista Saúde Pública, v. 29, n. 1, p. 424-433, 2006.

BAHIA, M.C. Mulheres no comando das organizações: um caso de polícia. 2002. Tese. (Doutorado em Administração) - Núcleo de Pós Graduação em Administração, Universidade Federal da Bahia, Salvador, 2002.

BAHIA. Lei no 11.370, de 04 de fevereiro de 2009. Estabelece a Lei Orgânica da Policia Civil do Estado da Bahia, Diário Oficial do Estado, 05 fev. 2009.

BRASIL. MINISTÉRIO DA JUSTIÇA. Secretaria Nacional de Segurança Pública. Relatório Técnico - Mapeamento dos Programas de Atenção à Saúde das Instituições Estaduais de Segurança Pública, 2009. Disponível em: <http://www.segurancacidada.org.br> Acesso em: 20 abr. 2009.

. MINISTÉRIO DA SAÚDE. Dados de Saúde Vigitel 2009.

Disponível em: <http://portal.saude.gov.br/portal/saude/profissional/ visualizar_texto.cfm?idtxt $=30864$ \&janela $=1>$ Acesso em: 27 nov. 2010.

BONELLI, M.G. Perfil social e de carreira dos delegados de polícia. In: Maria Tereza Sadek, organizadora. Delegados de Polícia. 1. ed. São Paulo: Sumaré: Fundação Ford, 2003. p. 31-67.

BRANT, L. C. ; DIAS, E. C. Trabalho e sofrimento em gestores de uma empresa pública em reestruturação. Cadernos de Saúde Pública, Rio de Janeiro, v. 20, n. 4, p. 942-949, 2004.

CALAZANS, M. E. A constituição de mulheres em policiais: um estudo sobre policiais femininas na Brigada Militar do Rio Grande do Sul. 2003. Dissertação (Mestrado em Psicologia) Programa de Pós- Graduação em Psicologia Social e Institucional, Universidade Federal Rio Grande do Sul, Porto Alegre, 2003.

COUTINHO, E. S. F; ALMEIDA-FILHO, N; MARI, J. J. Fatores de risco para morbidade psiquiátrica menor: resultados de um estudo transversal em três áreas urbanas do Brasil. Revista de Psiquiatria Clínica, n. 26, p. 246-256, 1999.

DEJOURS, C. A loucura do trabalho: estudo de psicopatologia do trabalho. São Paulo: Cortez: Oboré, 1992.

FERREIRA, D. K. S; AUGUSTO, L. G. S; SILVA, J. M. Trabalho e Saúde dos Policiais Militares do Recife-PE. In: Congresso 
Mundial de Epidemiologia, XVIII e Congresso Brasileiro de Epidemiologia, VII. Anais... Porto Alegre - Brasil, 2008.

FERNANDES, R.C.P. et al. Trabalho e cárcere: um estudo com agentes penitenciários da região metropolitana de Salvador, Brasil. Cadernos de Saúde Pública, n. 18, p. 807-816, 2002.

FERNANDEZ, M. M. Mujeres policía. Madrid, Centro de Investigaciones Sociologicas, Siglo XXI de Espana, 134 p. 1994.

GOLDEBERG, D.; HUXLEY, P. Common mental disorders a bio-social model. 2. ed. London: Tavistock:Routledge, 1993.

HAGEN, A. M. M. O trabalho policial: estudo da policia civil do estado do Rio Grande do Sul. 2005. Tese (Doutorado em Sociologia) Universidade Federal do Rio Grande do Sul, Porto Alegre 2005.

KARASEK, R.A. Job Content Questionnaire and User's Guide. Columbia University 1993. Disponível em: <www.jcqcenter.org.> Acesso em: 20 set. 2009.

KELLEY, T.M. Mental health and prospective police professionals. International Journal of Police Strategies \& Management. n.28, p.6-29, 2005.

LAVIGNE, E; BOURBONNAIS, R. Psychosocial work environment, interpersonal violence at work and psychotropic drug use among correctional officers. International Journal of Law and Psychiatry. v. 33, n. 2, p. 122-129, 2010.

MANSUR, J.; MONTEIRO, M. G. Validation of the "CAGE" alcoholism screening test in a Brazilian psychiatric inpatient hospital setting. Brazil Journal Medical and Biological Research, Ribeirão Preto, v. 16, n. 3, p. 215-218, 1983.

MARI, J. J.; WILLIAMS, P. A validity study of a psychiatric screening questionnaire (SRQ-20) in primary care in the city of São Paulo.

British Journal of Psychiatry, n. 148, p. 23-26, 1986.

MINAYO, M. C. S.; SOUZA, E. R. Missão investigar: entre o ideal e a realidade de ser policial. Rio de Janeiro: Garamond, 2003.

MINAYO, M. C. S.; SOUZA, E. R.; CONSTANTINO, P. (Coordenadoras). Missão prevenir e proteger: condições de vida, trabalho e saúde dos policiais militares do rio de janeiro. Rio de Janeiro: Editora Fiocruz. 2008. 328 p. 
MINAYO, M. C. S.; ASSIS, S. C.; OLIVEIRA, R. V. Impacto das atividades profissionais na saúde física e mental dos Policiais Civis e Militares do Rio de Janeiro. Ciência \& Saúde Coletiva. v. 16, n. 4, p. 2199-2209, 2011.

MORAES, L. F. R. et al. Implicações do gênero na qualidade de vida e estresse no trabalho da Polícia Militar do Estado de Minas Gerais. In: Congresso de Ciências Humanas, Letras e Artes, V. Anais... Ouro Preto/Mariana, Universidade Federal de Ouro Preto, p. 56, 2001.

PALMA, A. et al. Nível de ruído em ambiente de trabalho do professor de educação física em aulas de ciclismo indoor. Revista de Saúde Pública. v. 43, n. 2, p. 345-351, 2009.

PORTO, L. A. et al. Associação entre distúrbios psíquicos e aspectos psicossociais do trabalho de professores. Revista de Saúde Pública, v. 40, n. 5 p. 818-26, 2006.

REIS, E. J. F. B. et al. Trabalho e distúrbios psíquicos em professores da rede municipal de Vitória da Conquista, Bahia, Brasil. Cadernos de Saúde Pública, Rio de Janeiro, v. 21, n. 5, p. 1480-1490, 2005.

ROSA, A. R.; BRITO, M. J.; OLIVEIRA, F. M. Os Sentidos da Violência nas Organizações: uma Análise Construcionista da História de Vida de uma Policial Militar. Revista Eletrônica Gestão e Sociedade. v. 1, n. 1 jan./jun. 2007.

SANTOS, D. C. et al. Prevalência de transtornos mentais comuns em agentes penitenciários. Revista Brasileira de Medicina do Trabalho, v. 8, n. 1 p. 33-38, 2010.

SANTOS, K. O. B.; ARAÚJO, T. M.; OLIVEIRA, N. F. Estrutura Fatorial e Consistência Interna do Self Report Questionary (SRQ-20) em população urbana. Cadernos de Saúde Pública. Rio de Janeiro, v. 25, n. 1 p. 214-222, 2009.

SANTOS, I. S. et al. Comparing validity of Edinburg scale and SRQ20 in screening for post-partum depression. Clinical Practice and Epidemiology in Mental Health. n. 3, p. 18, 2007.

SADEK, M. T.; ARANTES, R. B. Delegados de Polícia: quem são e o que pensam. In Segurança Cidadã e Polícia na Democracia. Cadernos Adenauer, Rio de Janeiro, v. 4, n. 3, p. 57-70, 2003. SILVA, M. B.; VIEIRA, S. B. O processo de Trabalho do Militar Estadual e a Saúde Mental. Revista Saúde e Sociedade de São Paulo, v. 17, n. 4 p. 161-170, 2008. 
SILVEIRA, M. N. B. As Delegadas de Polícia de São Paulo: profissionalismo e gênero. 2009. Dissertação (Mestrado em Sociologia). Universidade Federal de São Carlos, São Paulo, 2009.

SOUZA, E. R. et al. Sofrimento psíquico entre policiais civis: uma análise sob a ótica de gênero. Cadernos de. Saúde Pública, v. 23 n. 1, p. 105-114, 2007.

SOUZA, E. R.; MINAYO, M. C. S. Policial, risco como profissão: morbimortalidade vinculada ao trabalho. Revista Ciência e Saúde Coletiva, v. 10, n. 4, p. 917-928, 2005.

SOUZA, E. R.; MINAYO, M. C. S.; ASSIS, S. G. Construção histórica de uma categoria social. In: MINAYO, M. C. S.; SOUZA, E. R. Missão investigar: entre o ideal e a realidade de ser policial. Rio de Janeiro: Garamond, p. 51-78, 2003.

STURAR, H. Suicidality among police. Current Opinion in Psychiatry, v. 21, n. 5 p. 505-509, 2008. 